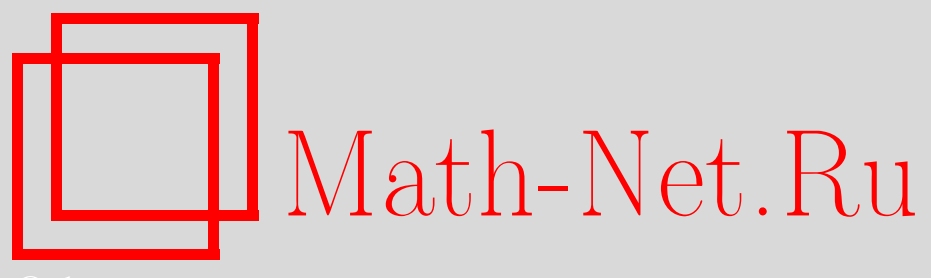

М. А. Всемирнов, Э. А. Гирш, Д. Ю. Григорьев, Г. В. Давыдов, Е. Я. Данцин, И. Д. Заславский, Э. Ф. Караваев, Б. Ю. Конев, Н. К. Косовский, В. А. Лифшиц, М. Маргенштерн, Ю. В. Матиясевич, Г. Е. Минц, В. П. Оревков, Р. Плюшкявичус, А. О. Слисенко, С. В. Соловьев, В. П. Чернов, Николай Александрович Шанин (некролог), УМН, 2013, том 68, выпуск 4, 173-176

DOI: https://doi.org/10.4213/rm9528

Использование Общероссийского математического портала Math-Net.Ru подразумевает, что вы прочитали и согласны с пользовательским соглашением http://www.mathnet.ru/rus/agreement

Параметры загрузки:

IP : 54.172 .240 .79

26 апреля 2023 г., 14:54:05

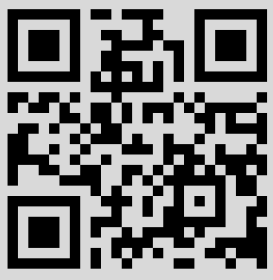




\section{Николай Александрович Шанин}

17 сентября 2011 г. скончался Николай Александрович Шанин, замечательный математик, педагог и человек.

Николай Александрович родился 25 мая 1919 г. в Пскове в семье врача. В 1935 г. он поступил на математико-механический факультет Ленинградского государственного университета, а в 1939 г. - в аспирантуру этого факультета. Его руководителем стал А.А. Марков, идеи и личность которого оказали решающее влияние на формирование научных интересов Николая Александровича. В 1942 г. Николай Александрович защитил кандидатскую диссертацию "О расширении топологических пространств", а в 1946 г. - докторскую диссертацию "О произведении топологических пространств". В 1941-1945 гг. Николай Александрович служил в Красной Армии. В октябре 1945 г. он стал стар-

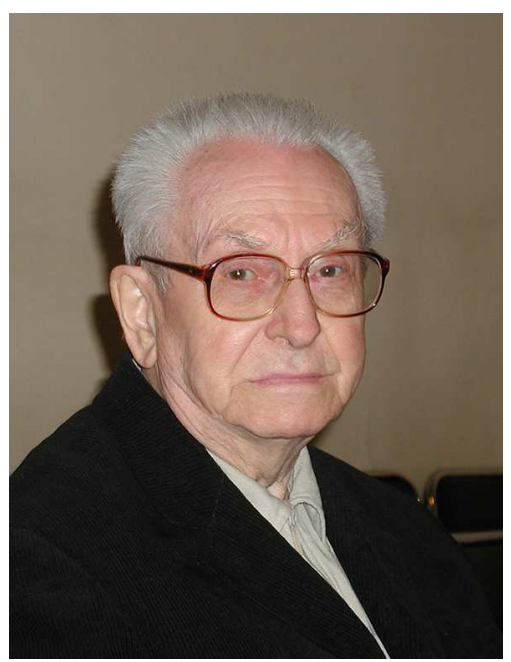
шим научным сотрудником Математического института им. В. А. Стеклова АН СССР, в Ленинградском/Петербургском отделении (ЛОМИ/ПОМИ) которого он работал до конца своей жизни. Работая в Академии наук, Николай Александрович многие годы также преподавал в Ленинградском/Санкт-Петербургском университете на математико-механическом и на философском факультетах; в 1957 г. ему было присвоено звание профессора.

Научную деятельность Николая Александровича можно разделить на два периода - топологический и логико-конструктивистский. Первый продолжался до конца 1940-х годов. Результаты Николая Александровича в общей топологии хорошо известны и не потеряли своего значения до наших дней. Здесь мы будем писать о втором периоде, в результате которого сформировалась ленинградская школа математической логики, теории доказательств и теории вычислимости.

В конце 1940-х годов Николай Александрович под влиянием Андрея Андреевича Маркова познакомился с идеями интуиционистского подхода к основаниям математики и пришел к необходимости переосмысления многих результатов "классической" математики и перехода к новой системе понятий и рассуждений, находящейся в конфликте с его предшествующим математическим опытом и содержанием его собственных топологических и теоретико-множественных работ.

Интерес Николая Александровича к вопросам обоснований и вопросам семантики касался не только математики, он был шире. Так, например, в курсе математической логики Николай Александрович подробно объяснял, как формируются базовые

DOI: $10.4213 / \mathrm{rm} 9528$ 
понятия и как возникает семантика бесконечного (к сожалению, его курс математической логики так и не был опубликован). Его комментарии о семантике естественного языка были оригинальны, остроумны и содержательны.

Мы не будем описывать работы Николая Александровича по логике и конструктивной математике, это можно найти в юбилейных статьях [1]-[3], а остановимся на том влиянии, которое Николай Александрович и его работы оказали на его учеников и исследователей в других странах.

Это влияние прослеживается по нескольким направлениям, которые, огрубляя, можно условно свести к двум отнюдь не изолированным друг от друга областям: одна из них - это конструктивизм и семантика, а другая - поиск логического вывода и теория доказательств. Собственные работы Николая Александровича не дают достаточно полного представления о том духе, той широте взглядов, которые царили вокруг него и привлекали молодежь.

Конструктивистские работы Николая Александровича начались с далеко идущего обобщения погружающих операций Гёделя-Колмогорова, цель которых - вычленить ту часть классической математики, прежде всего арифметики, которая верна и в интуиционистской логике. Эти работы привели Николая Александровича к алгоритму выявления конструктивной задачи, который сводит исходную задачу, скрытую в, вообще говоря, сложной формуле, к построению новых объектов и обоснованию суждения, которое само уже не содержит конструктивной задачи. В основу этого алгоритма было положено определение реализуемости арифметических формул, данное С. К. Клини в статье [4]. Николай Александрович сумел изменить это определение таким образом, что оно стало твердым основанием развития российской конструктивной школы. Он заметил, что добавление принципа Маркова (который не был частью интуиционистской математики или определения Клини) вместе с принципами, подсказанными интуитивным конструктивизмом, позволяет привести любое суждение к удобной нормальной форме $\exists x N(x)$, где $N(x)$ - "нормальная" формула, которая уже не содержит конструктивных связок существования и дизъюнкции. После того как найдено значение $x=m$, оставшуюся формулу $N(m)$ можно, в определенном смысле, понимать неконструктивно. А. А. Марков, которого не устраивало такое понимание, разработал в серии статей [5]-[12] эквивалентную конструктивную семантику нормальных формул.

Алгоритм выявления конструктивной задачи сильно облегчил общение российской конструктивной школы с конструктивистами Запада, в частности, с интуиционистами. Как очень быстро заметил С. К. Клини в статье [13], в чисто логических терминах этот алгоритм является следствием всего двух принципов - принципа Маркова и так называемого обобщенного тезиса Чёрча.

На основе разработанных принципов конструктивного понимания суждений Николай Александрович приступил к проведению программы конструктивизации математики, в первую очередь - математического и функционального анализа.

При реализации этой программы вопросы (алгоритмической) вычислимости, в частности алгоритмической разрешимости, играют ключевую роль. Поэтому Николай Александрович стимулировал изучение различных аспектов теории вычислимости и поддерживал интерес как к решению задач о вычислимости, так и к применению теоретических концепций к моделированию реальных процессов. Этот широкий взгляд на вещи привел в работах, выполненных ленинградской математической школой, среди прочего, к интересным результатам по применению канонических систем Поста к описанию экономических явлений и по разрешимым классам формул, а также к решению десятой проблемы Гильберта.

В конструктивизации математики вычислимость играет центральную роль. И по мере развития этого проекта естественно встал вопрос о соотношении вычислимости 
и практической эффективности. Обсуждение этого вопроса породило интерес к теории сложности вычислений, который вылился в многочисленные работы не только по сложности, но и по алгоритмике.

Все эти направления исследований тесно переплетались с проблемой поиска логического вывода, для разработки которой Николай Александрович создал в 1961 г. группу математической логики. Под руководством Николая Александровича и на основе его идей был разработан и реализован на тогдашних ЭВМ алгоритм АЛПЕВ (Алгоритм Логического Построения Естественного Вывода) для пропозициональной логики. Николай Александрович провидчески сделал акцент на использование эвристик и на результат в виде естественного вывода. Это, во-первых, дало алгоритм, который, судя по всему, был в те времена лучшим в мире, и во-вторых, обозначило действительно продуктивное направление теоретической и практической работы по разработке алгоритмов поиска вывода. Среди разнообразных влияний разработки компьютерного поиска вывода можно упомянуть использование компьютеров для решения математических проблем, которое до сих пор активно развивается в лаборатории математической логики ПОМИ.

В последний период своей научной деятельности Николай Александрович исследовал возможности развития конструктивной математики, особенно конструктивного анализа, средствами систем, финитных в смысле Гильберта (некоторые идеи Брауэра, к анализу которых Николай Александрович регулярно возвращался, также сыграли свою роль в этой работе). К этому циклу работ можно отнести и его конструкцию в статье [14], дающую, по существу, вариант теоремы Эрбрана для арифметики первого порядка.

Влияние лекций Николая Александровича выходило далеко за пределы математико-механического факультета и Математического института. Его ученики и аспиранты стали основателями школ математической логики в Литве и Армении. Заметным было и его влияние на развитие философской логики в Ленинграде/Петербурге. Научных "потомков" Николая Александровича сейчас можно найти по всему миру.

Научная и человеческая честность Николая Александровича вызывала уважение самых различных людей. Часто она затрудняла его жизнь, но иногда позволяла решать трудные научно-административные проблемы.

М. А. Всемирнов, Э.А. Гирш, Д. Ю. Григорьев, Г. В. Давыдов, Е.Я. Даниин, И.Д. Заславский, Э. Ф. Караваев, Б. Ю. Конев, Н. К. Косовский, В. А. Лифиич, M. Маргенштерн (M. Margenstern), Ю.В. Матиясевич, Г.Е. Мини, В.П. Оревков, Р. Плюшкявичус (R. Pliuškevičius), А.О. Слисенко, С.В. Соловъев, В.П. Чернов

\section{Список цитируемой литературы}

[1] С. Ю. Маслов, Ю.В. Матиясевич, Г.Е. Минц, В.П. Оревков, А. О. Слисенко, "Николай Александрович Шанин (к шестидесятилетию со дня рождения)", УМH, 35:2(212) (1980), 241-245; англ. пер.: S. Yu. Maslov, Yu. V. Matiyasevich, G. E. Mints, V.P. Orevkov, A. O. Slisenko, "Nikolai Aleksandrovich Shanin (on his sixtieth birthday)", Russian Math. Surveys, 35:2 (1980), 277-282.

[2] Ю. В. Матиясевич, Г. Е. Минц, В. П. Оревков, А. О. Слисенко, "Шанин Николай Александрович (к семидесятилетию со дня рождения)", УМН, 45:1(271) (1990), 205-206; англ. пер.: Yu. V. Matiyasevich, G. E. Mints, V. P. Orevkov, A. O. Slisenko, "Nikolai Aleksandrovich Shanin (on his seventieth birthday)", Russian Math. Surveys, 45:1 (1990), 239-240.

[3] М.А. Всемирнов, Э.А. Гирш, Д. Ю. Григорьев, Г. В. Давыдов, Е. Я. Данцин, А. А. Иванов, Б. Ю. Конев, В.А. Лифшиц, Ю. В. Матиясевич, Г. Е. Минц, 
В.П. Оревков, А. О. Слисенко, "Николай Александрович Шанин (к восьмидесятилетию со дня рождения)", УМН, 56:3(339) (2001), 181-184; англ. пер.: M. A. Vsemirnov, E. A. Hirsch, D. Yu. Grigor'ev, G. V. Davydov, E. Ya. Dantsin, A. A. Ivanov, B. Yu. Konev, V.A. Lifshits, Yu. V. Matiyasevich, G.E. Mints, V.P. Orevkov, A. O. Slisenko, "Nikolai Aleksandrovich Shanin (on his 80th birthday)", Russian Math. Surveys, 56:3 (2001), 601-605.

[4] S. C. Kleene, "On the interpretation of intuitionistic number theory", J. Symbolic Logic, 10:4 (1945), 109-124.

[5] А. А. Марков, "О языке Яо", Докл. АН СССР, 214 (1974), 40-43; англ. пер.: A. A. Markov, "On the language $Я_{0}$ ", Soviet Math. Dokl., 15 (1974), 38-42.

[6] А. А. Марков, "О языке Я1", Докл. АН СССР, 214 (1974), 279-282; англ. пер.: A. A. Markov, "On the language $Я_{1}$ ", Soviet Math. Dokl., 15 (1974), 125-128.

[7] А. А. Марков, "О языке Я2", Докл. АН СССР, 214 (1974), 513-516; англ. пер.: A. A. Markov, "On the language $Я_{2}$ ", Soviet Math. Dokl., 15 (1974), 184-188.

[8] А. А. Марков, "О языке Яз", Докл. АН СССР, 214 (1974), 765-768; англ. пер.: A. A. Markov, "On the language $Я_{3}$ ", Soviet Math. Dokl., 15 (1974), 242-246.

[9] А. А. Марков, "О языках $Я_{4}, Я_{5}, \ldots$.., Докл. АН СССР, 214 (1974), 1031-1034; англ. пер.: А. A. Markov, "On the languages $Я_{4}, Я_{5}, \ldots$ ", Soviet Math. Dokl., 15 (1974), 313-317.

[10] А. А. Марков, "О языке Я A. A. Markov, "On the language $Я_{\omega}$ ", Soviet Math. Dokl., 15 (1974), 356-359.

[11] А. А. Марков, "О языке $Я_{\omega \mid}$ ", Докл. АН ССCP, 215 (1974), 57-60; англ. пер.: A. A. Markov, "On the language $Я_{\omega \mid}$ ", Soviet Math. Dokl., 15 (1974), 443-447.

[12] А.А. Марков, "О полноте классического исчисления предикатов в конструктивной математической логике”, Докл. АН СССР, 215 (1974), 266-269; англ. пер.: A. A. Markov, "On the completeness of the classical predicate calculus in constructive mathematical logic", Soviet Math. Dokl., 15 (1974), 476-481.

[13] S. C. Kleene, "Realizability and Shanin's algorithm for the constructive deciphering of mathematical sentences", Logique et Anal. (N.S.), 3 (1960), 154-165.

[14] Н. А. Шанин, "Об иерархии способов понимания суждений в конструктивной математике", Проблемы конструктивного направления в математике. 6, Тр. МИАН СССР, 129, 1973, 203-266; англ. пер.: N. A. Shanin, "On a hierarchy of ways of understanding judgments in constructive mathematics", Proc. Steklov Inst. Math., 129 (1973), 209-271.

\section{Список научных трудов Н. А. Шанина*}

[48] N. A. Shanin, "On a finitary version of mathematical analysis", Ann. Pure Appl. Logic, 113:1-3 (2002), 261-295.

[49] N. A. Shanin, "On base representations of finitary mathematics", Methods of logic in mathematics III, Abstracts (St. Petersburg, 2006), St. Petersburg, 2008, 14-16.

*Начало списка опубликовано в Математика в СCCP за сорок лет. 1917-1957, m. 2: Библиография, Физматгиз, М., 1959, 764-765; Математика в СССР, 1958-1967, m. 2, Наука, М., 1970, 764-765; УМН, 35:2(212) (1980), 245; 45:1(271) (1990), 206; 56:3(339) (2001), 184. Полный список публикаций и некоторые из них доступны на сайте http://logic.pdmi.ras.ru/ shanin. Там же приведены дополнительные биографические данные и фотографии. 